\title{
The structure and location of 18-crown-6 ether in zeolites RHO and ZK-5
}

\author{
Antony Nearchou, ${ }^{a}$ Catherine Dejoie, ${ }^{b}$ Paul R. Raithby ${ }^{\mathrm{a}}$ and Asel Sartbaeva ${ }^{\mathrm{a}}$ \\ a University of Bath, Department of Chemistry, Claverton Down, Bath, BA2 7AY, UK. \\ ${ }^{b}$ European Synchrotron Radiation Facility, 71 avenue des Martyrs, 38000, Grenoble, France
}

\begin{abstract}
The use of organic additives presents the greatest versatility and control of zeolite synthesis in order to prepare novel architectures for desired applications. Despite this prospect, there is little clarity of how organic additives are involved in framework assembly and the range of behaviours that are available. To address this issue, we have considered zeolites RHO and ZK-5 which can both be prepared using 18-crown-6 ether as an additive. Previously, this additive has shown to employ different structure directing behaviours to assemble a variety of zeolites. We have used high resolution powder $\mathrm{X}$-ray diffraction and Rietveld refinement to determine structural models for zeolites RHO and ZK-5 with 18-crown- 6 ether occluded in the framework. In doing so, we can observe the identity, location and orientation of the occluded additive and reason the structure directing behaviour in synthesis. We report that the isolated 18 -crown- 6 ether molecule is involved in the assembly of zeolite RHO, and for zeolite ZK-5 it is the $\mathrm{K}^{+}$coordinated macrocation. In both cases the relevant additive is disordered in the framework, suggesting that they behave as spacefilling species that stabilise the formation of the $\alpha$-cage.
\end{abstract}

\section{Introduction}

Zeolites are crystalline aluminosilicate minerals, known for their microporosity and pervasive use as molecular sieves, adsorbents and catalysts. ${ }^{1}$ One of their most renowned uses is as catalysts for hydrocracking in the petrochemical industry, ${ }^{2}$ however there is ongoing research into using zeolites for hydrogen fuel storage, ${ }^{3}$ carbon dioxide capture ${ }^{4}$ and selective extraction of radionuclides. ${ }^{5}$ Their structure consists of a three-dimensional framework built from silica and alumina $\mathrm{TO}_{4}$ tetrahedra ( $\mathrm{T}$ $=\mathrm{Si}$ or Al) that are connected via a shared apical oxygen atom. Within the structure, it can be recognised that the $\mathrm{TO}_{4}$ tetrahedra arrange themselves into regular geometric subunits, which are referred to as secondary building units (SBUs). ${ }^{6}$

Energetically, zeolites are recognised as being metastable and it is the stabilisation of the open framework cavities that is an integral factor dictating the crystallisation process. Species that provide such a structure stabilising effect are known as structure directing agents (SDAs). ${ }^{7,8}$ In natural occurring zeolite formation this stabilisation is achieved by metal cations which use electrostatic interactions to stabilise the voids and guide the assembly of certain SBUs. ${ }^{9}$ For the preparation of synthetic zeolites, we can employ the use of organic additives that use a mixture of electrostatic, van der Waals and hydrogen bonding interactions to direct structure. ${ }^{10-12}$ Although the available nonbonding interactions between organic additives and the growing zeolite framework are known there is little clarity on how exactly this impacts the zeolite crystallisation process. This is particularly important if we are to rationally traverse the metastable zeolite synthesis landscape and prepare new zeolite architectures for intended applications. The prevalent use of organic additives is best illustrated by the fact that less than 30 of the 255 zeolitic frameworks recognised by the International Zeolite Association can be synthesised in the absence of an organic additive. ${ }^{13,14}$ 
Davis and Lobo ${ }^{15,16}$ suggest that the potential behaviour of organic additives can divided into three classifications: true templates, organic structure directing agents (OSDAs) and space-filling species. True templates are seen to employ strong interactions and imprint their symmetry onto the growing framework. The discrepancy between OSDAs and templates is unclear, but the former is attributed by weaker interactions and an absence of symmetric or geometric matchup. Lastly, space-filling species are recognised by weak interactions and occupy the framework void spaces rather than being forthrightly involved in directing assembly. Despite these recognised categories, additional additive roles such as "structure-blocking"17, 18 and influence on the free-energy landscape of crystallisation ${ }^{19,20}$ have been suggested but have received little research. Currently, computational calculations and synthetic approaches only consider the templating roles of organic species to rationally predict the ideal additives to prepare new zeolites. ${ }^{21-23}$ However, a much wider appreciation of the structure directing capabilities of organic additives is required to take full advantage of their use in zeolite design.

18-crown- 6 ether (18C6) is an example of an organic additive that can be used in the synthesis of multiple zeolites with a variety of topologies. ${ }^{24-27}$ Previously, it has been observed that $18 \mathrm{C} 6$ can undertake differing roles in the synthesis of the polymorphic EMT and FAU-type zeolites. ${ }^{20,28}$ Although in both the $18 \mathrm{C} 6$ exists as a $\left[(18 \mathrm{C} 6) \mathrm{Na}^{+}\right]$macrocation, it is a true geometric template for the synthesis of EMT-type zeolites and a space-filling species in the synthesis of FAU-type zeolites. ${ }^{29-}$ ${ }^{33}$ This is important, as it demonstrates the integral role of $18 \mathrm{C} 6$ in the synthesis mechanism to differentiate between the two polymorphs. Zeolites RHO and ZK-5 (KFI) are two zeolites that can also be prepared using $18 \mathrm{C} 6,{ }^{24,26}$ however the role, identity and location of the $18 \mathrm{C} 6$ species has not been determined. Figure 1 shows the framework structure of these two zeolites, in addition to the constituent SBUs. Both zeolites consist of $\alpha$-cages in a body centred cubic arrangement and it is these $\alpha$-cages that the $18 \mathrm{C} 6$ is believed to occupy, ${ }^{33,34}$ however it has not been explicitly proven. Due to the lack of structural information, there is currently no understanding of how the $18 \mathrm{C} 6$ molecule is involved in the synthesis of these two zeolites in comparison to the FAU and EMT-type zeolites.

For the first time, we report the crystal structure of zeolites RHO and ZK-5 with the $18 \mathrm{C} 6$ species occluded within their zeolite frameworks. We present experimental evidence that the $18 \mathrm{C} 6$ molecule occupies the $\alpha$-cage cavities in both zeolites, in addition to what cations the molecule is coordinated to. Using these structures, we have gleaned the role of the $18 \mathrm{C} 6$ organic additive throughout the crystallisation of both zeolites. 
RHO

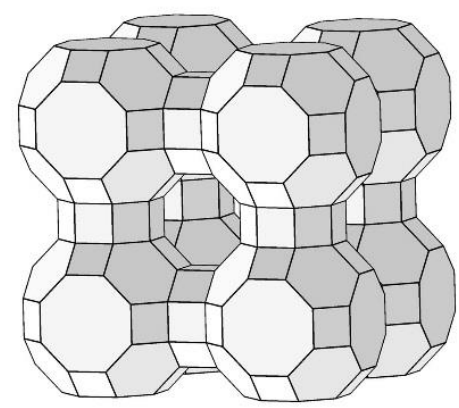

KFI

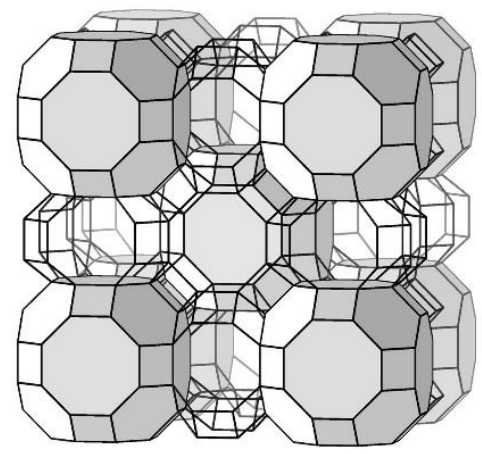

Constituent SBUs

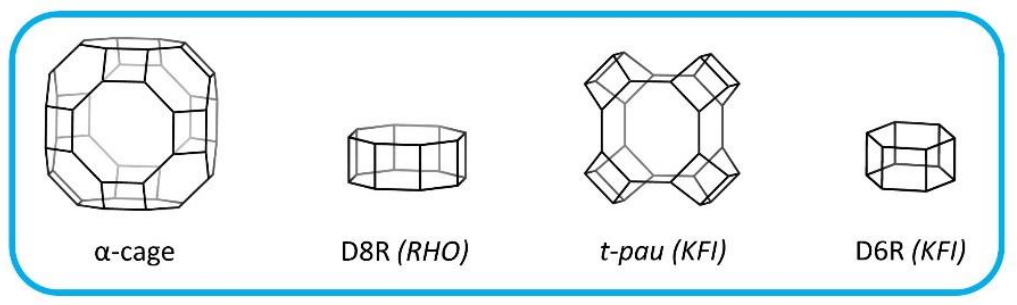

Figure 1. Structure of the RHO and KFI framework types. Included are the constituent SBUs: the $\alpha$-cage, the double 8-ring (D8R), t-pau unit and the double 6-ring (D6R). For the latter three the code in parenthesis indicates the framework that this SBU belongs to exclusively. The framework structures are shown with the $\alpha$-cages and D8Rs as solid polyhedra.

\section{Methods}

\section{Sample Preparation}

The zeolite RHO and ZK-5 samples were synthesised using the verified procedures reported by Chatelain et al. ${ }^{24,26,27,34}$ using 18-crown-6 ether (18C6) as organic additive. The molar batch compositions used in the synthesis of each zeolite is shown in table 1 . The materials used for sample preparation were sodium hydroxide $(\mathrm{NaOH})$, potassium hydroxide $(\mathrm{KOH})$, strontium nitrate $\left(\mathrm{Sr}\left(\mathrm{NO}_{3}\right)_{2}\right)$, caesium hydroxide solution ( $50 \mathrm{wt} \% \mathrm{CsOH}$ in water), 18-crown-6 ether $\left(\mathrm{C}_{12} \mathrm{H}_{24} \mathrm{O}_{6}, 18 \mathrm{C} 6\right)$, sodium aluminate $\left(\mathrm{NaAlO}_{2}\right)$, aluminium hydroxide $\left(\mathrm{Al}(\mathrm{OH})_{3}\right)$, colloidal silica (LUDOX ${ }^{\circledR} \mathrm{HS}-40,40 \mathrm{wt} \%$ $\mathrm{SiO}_{2}$ in water) and deionised water. Aside from the deionised water, all the materials used were purchased from Sigma-Aldrich.

Table 1. Hydrogel batch compositions used to prepare zeolites RHO and ZK-5.

\begin{tabular}{ccccccccc}
\hline Zeolite & $\mathrm{Al}_{2} \mathrm{O}_{3}$ & $\mathrm{Na}_{2} \mathrm{O}$ & $\mathrm{K}_{2} \mathrm{O}$ & $\mathrm{SrO}$ & $\mathrm{Cs}_{2} \mathbf{O}$ & $\mathbf{S i O}_{2}$ & $\mathbf{1 8 C 6}$ & $\mathbf{H}_{2} \mathbf{O}$ \\
\hline $\mathrm{RHO}$ & 1 & 1.8 & & & 0.3 & 10 & 0.50 & 100 \\
ZK-5 & 1 & & 2.7 & 0.1 & & 10 & 1.0 & 220 \\
\hline
\end{tabular}

\section{$\underline{\text { Zeolite RHO }}$}

Zeolite RHO was prepared as follows. First the sodium and caesium hydroxide were added to the deionised water, followed by the addition of the 18C6. Upon complete dissolution the sodium 
aluminate was added, and the mixture permitted to stir until it was homogeneous. Next the colloidal silica was slowly poured into the solution under stirring, to negate any rapid gelation. The produced hydrogel was then aged under stirring at ambient conditions for 24 hours. After aging, the hydrogel was transferred to a Teflon cup within a stainless-steel autoclave and heated at $110^{\circ} \mathrm{C}$ for 8 days. Following heating, the autoclave was removed from the oven and left to cool to the ambient temperature. The crystallised zeolite product was subsequently separated from the mother liquor via Buchner filtration, and washed with distilled water until the $\mathrm{pH}$ of the filtrate was neutral. The product was then dried at $90^{\circ} \mathrm{C}$, before being ground prior to further calcination and dehydration.

\section{$\underline{\text { Zeolite ZK-5 }}$}

The zeolite ZK-5 precursor hydrogel was prepared by first dissolving the potassium hydroxide in a portion of the distilled water. To this solution the aluminium hydroxide was added, and then dissolved under stirring and heating to near $110^{\circ} \mathrm{C}$. After dissolution, the solution was cooled to ambient temperature and replenished with any water loss via evaporation during heating. In a separate vessel the $18 \mathrm{C} 6$ and strontium nitrate were dissolved in the second portion of distilled water. The colloidal silica was then poured into this solution and stirred until homogeneous. Next the previously prepared alumina solution was rapidly poured into the silica solution under stirring, to produce the hydrogel which was aged under stirring for 30 minutes. After aging, the hydrogel was transferred to a Teflon cup within a stainless-steel autoclave and heated at $150^{\circ} \mathrm{C}$ for 5 days. Following heating, the autoclave was removed from the oven and cooled to ambient temperatures. To retrieve the as-synthesised zeolite ZK-5 sample the same process of separation, washing and drying performed for zeolite RHO was used.

\section{Calcination and Dehydration}

The as-synthesised sample of each zeolite was divided into two halves, to produce the filled and empty analogues. The filled analogue being as-synthesised with the $18 \mathrm{C} 6$ intact, and the empty analogue having been calcined so as to remove occluded $18 \mathrm{C} 6$.

Calcination was achieved by heating the relevant analogue in a tube furnace under air to $450^{\circ} \mathrm{C}$ for 6 hours at a ramp rate of $1 \mathrm{Kmin}^{-1}$. Throughout this heating cycle the temperature was held static at $100^{\circ} \mathrm{C}, 200^{\circ} \mathrm{C}$ and $300^{\circ} \mathrm{C}$ for 1 hour each. After calcination the sample was cooled at a rate of $1 \mathrm{Kmin}^{-1}$ to ambient conditions, including a static stage at $200^{\circ} \mathrm{C}$ for 1 hour.

Based on sample conditions on the respective diffractometers, only the zeolite RHO empty and filled samples were dehydrated in preparation for measurements. This was performed by heating the samples in a tube furnace under vacuum. The heating cycle consisted of a ramp rate of $1 \mathrm{Kmin}^{-1}$, with static temperatures stages of $100^{\circ} \mathrm{C}$ for 1 hour and $200^{\circ} \mathrm{C}$ for 6 hours. Following this, the sample was then cooled at a rate of $1 \mathrm{Kmin}^{-1}$ to ambient conditions, including a static stage at $100^{\circ} \mathrm{C}$ for 1 hour during this cooling cycle. The dehydrated sample was then transferred under vacuum to a dry argon glove box and sealed into a glass vial under argon gas.

\section{High Resolution Powder X-ray Diffraction}

Both the empty and filled analogues of zeolites $\mathrm{RHO}$ and ZK-5 were analysed using high resolution powder X-ray diffraction. The diffraction patterns for the dehydrated zeolite RHO samples were 
recorded on the ID22 beamline at the European Synchrotron Radiation Facility (ESRF) in Grenoble, France. The detector parameters were calibrated with silicon and the incident $\mathrm{X}$-ray radiation had a wavelength of $0.49598 \AA$. The samples were loaded into $1 \mathrm{~mm}$ diameter borosilicate capillaries within an inert nitrogen atmosphere to prevent any sample hydration. The capillaries were subsequently sealed with vacuum grease and wax, before being mounted onto the diffractometer and cooled to $100 \mathrm{~K}$ using a liquid-helium-cooled cryostat. A scan range of $2 \theta=0.5-45.0^{\circ}$ and step size of $0.002^{\circ}$ were used, equating to a scan length of approximately 22 minutes. Throughout scanning the capillaries were spun perpendicular to the $\mathrm{X}$-ray beam to reduce preferred orientation effects.

The hydrated zeolite ZK-5 samples were analysed using a STOE STADI MP diffractometer, equipped with a MYTHEN2 $1 \mathrm{~K}$ silicon strip detector. The incident $\mathrm{X}$-ray radiation was pure $\mathrm{Cu} \mathrm{K} \alpha 1$, of wavelength $1.5406 \AA$, obtained using a Cu X-ray tube and a Ge(111) monochromator. A scan range of $2 \theta=3-100^{\circ}$, step size of $0.015^{\circ}$ and scan length of 13.6 hours were used. The diffraction measurements were obtained in the Debye-Scherrer mode, using a transmission sample holder between two foil insets with $3 \mathrm{~mm}$ masks. The diffraction patterns were recorded at ambient temperature.

The patterns obtained from both diffractometers were used for structure determination, using the Rietveld method in the TOPAS Academic software. ${ }^{35}$ The starting structures used were the crystal structures of zeolite RHO in the $I \overline{4} 3 \mathrm{~m}$ symmetry and the synthetic (Cs, K)-ZK5 zeolite, both reported by Parise et al. ${ }^{36,37}$ For the latter ZK5 zeolite structure, the Cs sites were substituted with $\mathrm{K}$ sites prior to the refinement process. First the structure of the empty analogues of zeolites RHO and ZK- 5 were determined, and these models used as the starting structures for the respective filled analogues.

The Rietveld refinements were performed using the $2 \theta=5.0-25.0^{\circ}$ and $2 \theta=14.0-69.0^{\circ}$ data ranges for the zeolite RHO and ZK-5 samples accordingly. During the refinement process 100,000 iterations were used, in addition to a $\chi^{2}$ convergence criteria of 0.001 . The quality of the Rietveld fit was evaluated using the goodness of fit factor $G$, equal to $R_{w p} / R_{\text {exp }}{ }^{38}$ The average mean-square displacement in all directions $B_{\text {eq, }}$, was used to assess the degree of atomic displacement. ${ }^{39} \mathrm{~A}$ summary of the refinement process and profile functions are included in the Supplementary Information (SI).

\section{Results}

\section{Zeolite RHO}

The powder X-ray diffraction patterns and final Rietveld fits for both the empty and filled zeolite RHO samples are shown in figures 2 and 3 respectively. These figures also include the goodness of fit $G$ value for the Rietveld fits, as well as the difference between the experimental data and the fit. Tables 2 and 3 contain the final refined unit cell parameters and crystallographic data for the empty and filled zeolites accordingly. Both zeolites were fit using the $I \overline{4} 3 \mathrm{~m}$ space group as opposed to the ambient higher symmetry $\operatorname{Im} \overline{3} m$ space group that zeolite RHO is typically reported in, ${ }^{40,41}$ as shown in figure 1. However, there is substantial evidence in the literature where the symmetry is lowered due to certain stimuli, such as dehydration ${ }^{36}$ and low temperatures ${ }^{42}$ which are relevant here, as well as applying mechanical pressure. ${ }^{43,44}$ The $I \overline{4} 3 \mathrm{~m}$ symmetry is characterised by elliptical deformations in the 8-ring apertures, as illustrated in figure 4. 


\section{Empty Zeolite RHO}

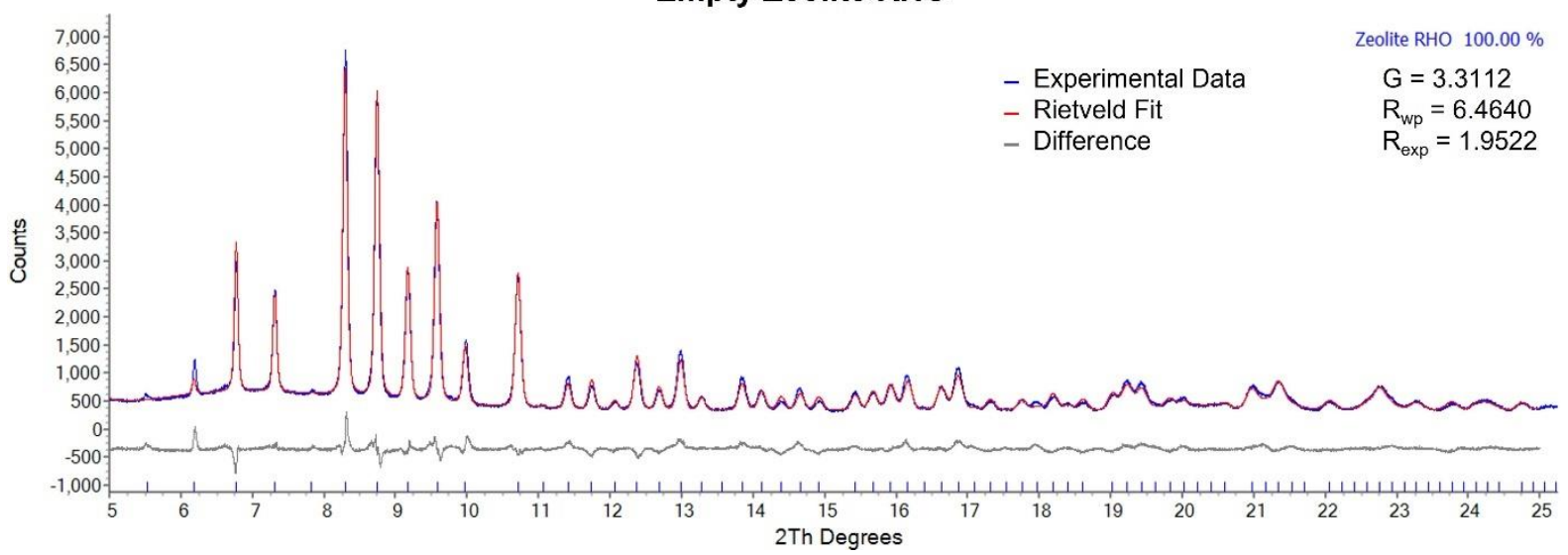

Figure 2. Powder X-ray diffraction patterns for the empty zeolite RHO sample. The experimental data is shown in blue, the Rietveld fit in red and the difference between the two in grey.

\section{Filled Zeolite RHO}

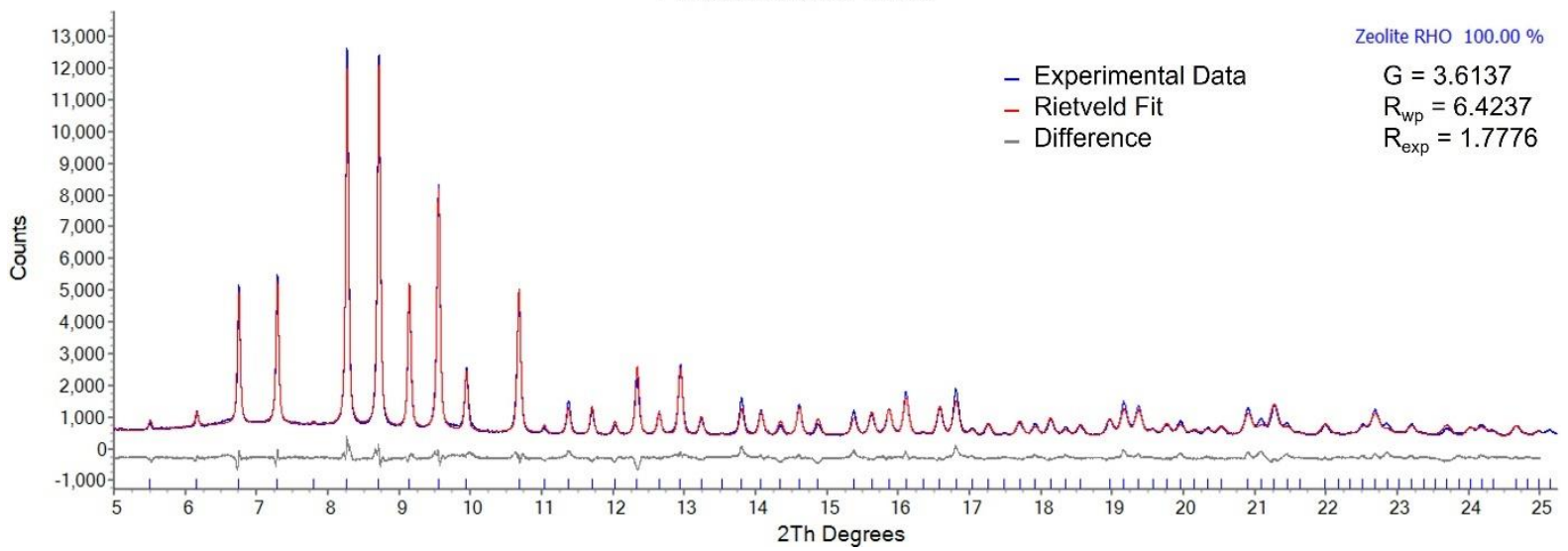

Figure 3. Powder X-ray diffraction patterns for the filled zeolite RHO sample. The experimental data is shown in blue, the Rietveld fit in red and the difference between the two in grey.

Table 2. Final refined unit cell parameters and crystallographic sites for the empty zeolite RHO sample. 'Occ.' refers to the fractional occupancy of the relevant crystallographic site.

\begin{tabular}{|c|c|c|c|c|c|}
\hline \multirow{3}{*}{\multicolumn{2}{|c|}{$\begin{array}{c}\text { Symmetry } \\
\text { Cubic } \\
I \overline{4} 3 m\end{array}$}} & \multicolumn{2}{|c|}{ Unit Cell } & \multicolumn{2}{|c|}{ Refinement } \\
\hline & & \multirow[t]{3}{*}{$a / \AA ̊$} & \multirow[t]{3}{*}{$14.5457(1)$} & G & 3.3112 \\
\hline & & & & $\mathrm{R}_{\mathrm{wp}}$ & 6.4640 \\
\hline & & & & $\operatorname{Rexp}$ & 1.9522 \\
\hline Atom & $x$ & $y$ & $z$ & Occ. & $B_{\text {eq }}$ \\
\hline $\mathrm{Si}$ & $0.2691(1)$ & $0.1216(1)$ & $0.4225(1)$ & $0.860(28)$ & $0.64(3)$ \\
\hline $\mathrm{Al}$ & $0.2691(1)$ & $0.1216(1)$ & $0.4225(1)$ & $0.140(28)$ & $0.64(3)$ \\
\hline $\mathrm{O}(1)$ & $0.2181(1)$ & $0.2181(1)$ & $0.4046(1)$ & 1 & $0.54(5)$ \\
\hline$O(2)$ & $0.1261(1)$ & $0.1261(1)$ & $0.6182(1)$ & 1 & $0.54(5)$ \\
\hline $\mathrm{O}(3)$ & $0.0345(2)$ & $0.2085(2)$ & $0.3870(2)$ & 1 & $0.54(5)$ \\
\hline Cs & 0 & 0 & 0.5 & $0.648(1)$ & $11.45(5)$ \\
\hline $\mathrm{Na}$ & 0.3333 & 0.3333 & 0.3333 & $0.170(6)$ & $0.15(64)$ \\
\hline
\end{tabular}


Table 3. Final refined unit cell parameters and crystallographic sites for the filled zeolite RHO sample. 'Occ.' refers to the fractional occupancy of the relevant crystallographic site.

\begin{tabular}{|c|c|c|c|c|c|}
\hline \multicolumn{2}{|c|}{ Symmetry } & \multicolumn{2}{|c|}{ Unit Cell } & \multicolumn{2}{|c|}{ Refinement } \\
\hline \multirow{3}{*}{\multicolumn{2}{|c|}{$\begin{array}{l}\text { Cubic } \\
I \overline{4} 3 m\end{array}$}} & \multirow[t]{3}{*}{$a / \AA$} & \multirow[t]{3}{*}{$14.59248(7)$} & G & 3.6137 \\
\hline & & & & $\mathrm{R}_{w p}$ & 6.4237 \\
\hline & & & & $R_{\exp }$ & 1.7776 \\
\hline Atom & $x$ & $y$ & $Z$ & Occ. & $B_{\text {eq }}$ \\
\hline $\mathrm{Si}$ & $0.2706(1)$ & $0.1202(1)$ & $0.4220(1)$ & $0.859(29)$ & $-0.34(3)$ \\
\hline $\mathrm{Al}$ & $0.2706(1)$ & $0.1202(1)$ & $0.4220(1)$ & $0.141(29)$ & $-0.34(3)$ \\
\hline $\mathrm{O}(1)$ & $0.2181(1)$ & $0.2181(1)$ & $0.4046(1)$ & 1 & $-0.49(5)$ \\
\hline $\mathrm{O}(2)$ & $0.1261(1)$ & $0.1261(1)$ & $0.6182(1)$ & 1 & $-0.49(5)$ \\
\hline $\mathrm{O}(3)$ & $0.0316(2)$ & $0.2133(2)$ & $0.3905(2)$ & 1 & $-0.49(5)$ \\
\hline Cs & 0 & 0 & 0.5 & $0.923(1)$ & $5.49(4)$ \\
\hline $\mathrm{Na}$ & 0.3333 & 0.3333 & 0.3333 & $0.306(9)$ & $11.4(11)$ \\
\hline$C(1)$ & 0.3333 & 0.6667 & 0.5 & $1.000(26)$ & $20.0(5)$ \\
\hline$C(2)$ & $0.4501(13)$ & $0.4501(13)$ & $0.6992(24)$ & $0.727(26)$ & $20.0(7)$ \\
\hline $\mathrm{Oc}(1)$ & $0.4552(7)$ & $0.4552(7)$ & $0.3598(11)$ & $0.540(22)$ & $17.2(7)$ \\
\hline $\mathrm{Oc}(2)$ & 0.6667 & 0.3333 & 0.3333 & $1.000(30)$ & 19.2(8) \\
\hline
\end{tabular}

\section{Metal Cations}

Two crystallographic metal cation sites were determined in both zeolite RHO structures - these being $\mathrm{a} \mathrm{Cs}^{+}$and a $\mathrm{Na}^{+}$site. Both cation sites were seen to occupy special positions in the structure and are shown in figure 4 for the empty zeolite. The Cs site is positioned at the centre of the distorted double 8-ring (D8R) units, between the elliptical 8-ring apertures. Alternatively, the Na site is associated with the single 6 -ring (S6R) faces of the $\alpha$-cage. The Na sites are located within the interior of an $\alpha$-cage if the associated S6R face is connected to the minor axis of the elliptical 8-ring aperture. Both cation sites are comparable to those reported by Robson et al. ${ }^{41}$ in the ambient $\operatorname{Im} \overline{3} m$ space group, despite the difference in symmetry. The only distinctions are that in the Robson structure the Cs site is located in the centre of each 8-ring aperture, and a Na site is observed on either side of the S6R faces.

Site Cs

Occ. $0.648(1)$

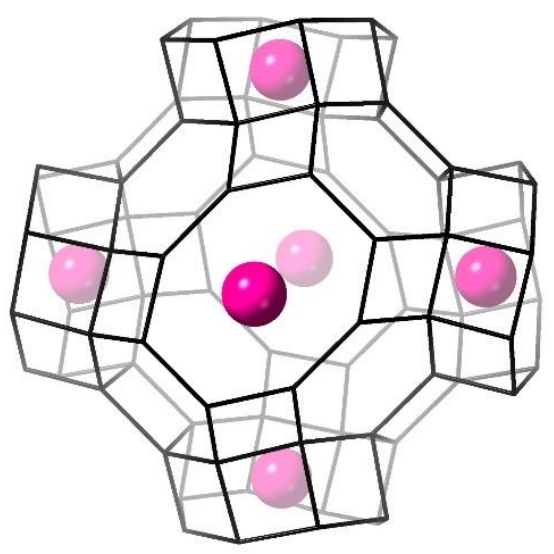

Site $\mathrm{Na}$

Occ. $0.170(6)$

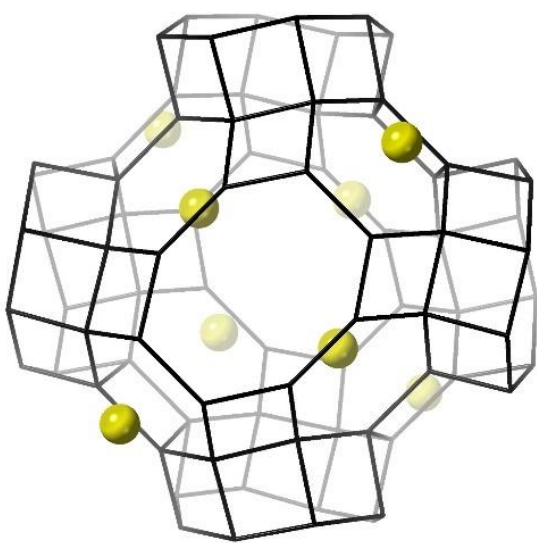

Figure 4. Location of the Cs and Na cation sites determined in the empty zeolite RHO. The framework is shown as a stick model, the caesium cations as pink spheres and the sodium cations in yellow. Also included is the fractional occupancy (Occ.) of each site. 
For the occluded $18 \mathrm{C} 6$ species four crystallographic sites were determined, consisting of the carbon $C(1) C(2)$ sites and the oxygen $\operatorname{Oc}(1) \operatorname{Oc}(2)$ sites. The atomic identity of the sites was assessed based on the goodness of fit, interatomic distances and the rationale that there should be approximately twice as many carbons present compared to oxygen based on the chemical formula of $18 \mathrm{C} 6$. Figure 5 illustrates the location of these four crystallographic sites in the filled zeolite RHO structure. It was observed that the sites are best described as a cluster within the interior of the $\alpha$-cage. This contrasts the structure of $18 \mathrm{C} 6$ within zeolite EMC-2 reported by Baerlocher et al. ${ }^{29}$ where a discrete planar molecule is seen within the framework structure. We expect that the disorder seen in zeolite RHO is likely due to the cubic symmetry of the framework, meaning that the $18 \mathrm{C} 6$ molecule is not aligned along a single crystallographic axis as it is in the hexagonal zeolite EMC-2. Consequently, the periodic structure is an average of the different $18 \mathrm{C} 6$ orientations between adjacent unit cells.

Site $\mathbf{C}(1)$

Occ. $1.000(26)$

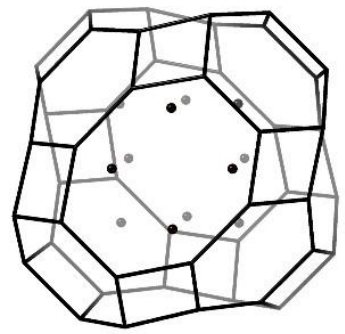

Site $\mathbf{C}(2)$

Occ. $0.727(26)$

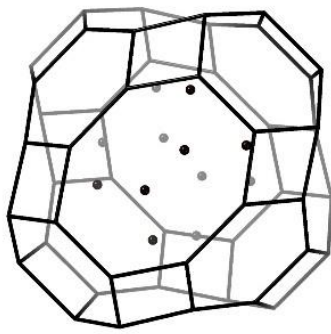

Site Oc(1)

Occ. $0.540(22)$

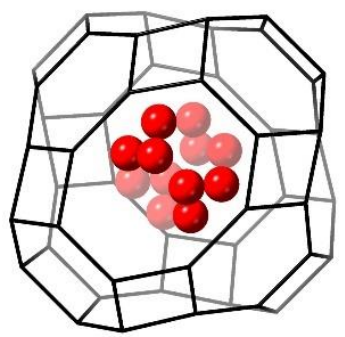

Site $\mathrm{Oc}(2)$

Occ. $1.000(30)$

Figure 5. Location of the $C(1), C(2), O c(1)$ and $O c(2)$ sites of the $18 \mathrm{C} 6$ oxyethylene chain in the filled zeolite RHO. The framework is shown as a stick model, the carbon sites as black spheres and the oxygen sites as red spheres. Also included is the fractional occupancy (Occ.) of each site.

The structure of the $18 \mathrm{C} 6$ cluster consists of a central core of twelve Oc(1) oxygen sites, each with an occupancy of approximately $54 \%$. This core is then surrounded by a shell of twelve $C(1)$ and twelve $C(2)$ sites, having occupancies of $100 \%$ and $73 \%$ respectively. Lastly, the cluster possesses an outer shell of four $\operatorname{Oc}(2)$ sites in a tetrahedral arrangement and an occupancy of $100 \%$ each. This results in a higher population of carbon atoms compared to oxygen, as anticipated for the $18 \mathrm{C} 6$ oxyethylene chain. The observed fractional occupancies suggest that there is more than a single $18 \mathrm{C} 6$ molecule per $\alpha$-cage, however based on the disorder of the cluster itself this cannot be confirmed. It is worth noting that there is an absence of a coordinated metal cation in the centre of the $18 \mathrm{C} 6$ cluster, as is seen in zeolite EMC-2. ${ }^{29}$ This suggests that it is the isolated $18 \mathrm{C} 6$ molecule, as opposed to a macrocation complex, that is involved in assembly of the RHO framework.

\section{$\underline{\text { Zeolite ZK-5 }}$}

Figures 6 and 7 show the powder X-ray diffraction patterns and final Rietveld fits for the hydrated empty and filled zeolite ZK-5 samples accordingly. Included is a plot of the difference between the experimental data and the fit, in addition to the model's goodness of fit $G$ value. The final refined crystallographic coordinates and unit cell parameters for the empty and filled samples are displayed in tables 4 and 5 respectively. Both zeolites were fit using the $\operatorname{Im} \overline{3} m$ space group, which is the ambient symmetry anticipated for zeolite ZK- $5.37,43,45$ 


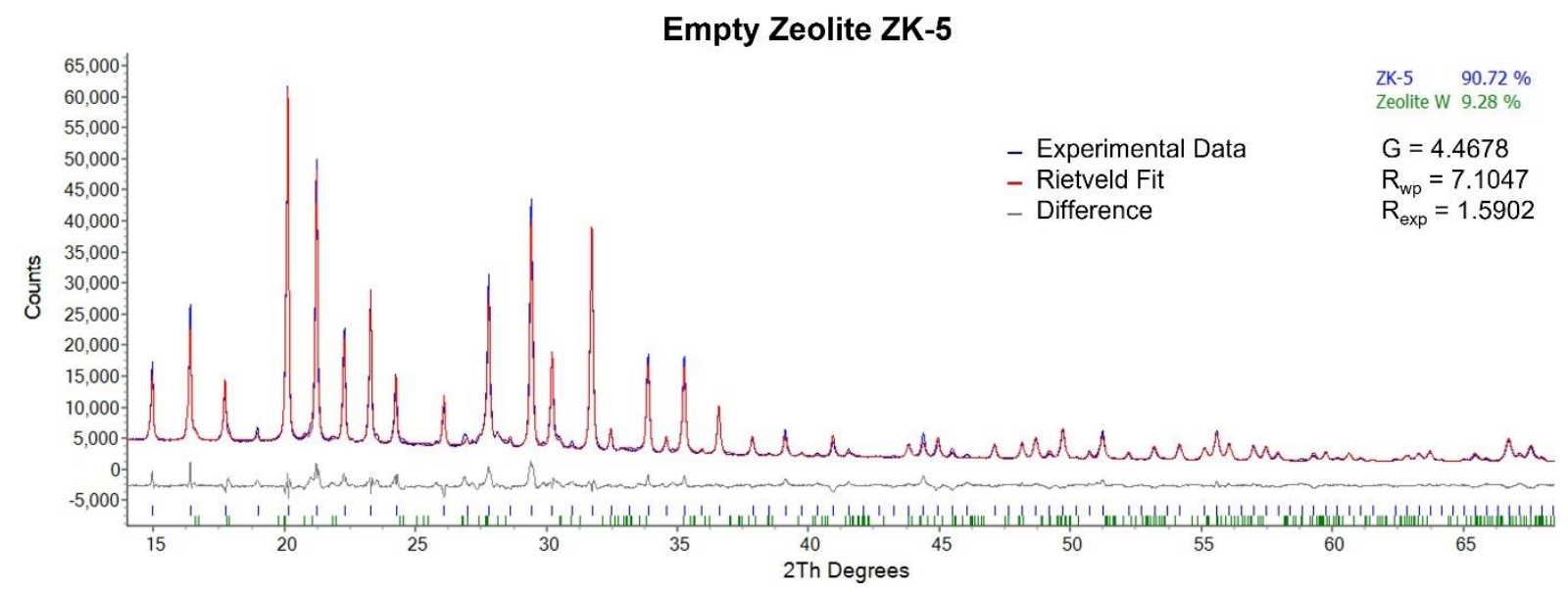

Figure 6. Powder X-ray diffraction patterns for the empty zeolite ZK-5 sample. The experimental data is shown in blue, the Rietveld fit in red and the difference between the two in grey.

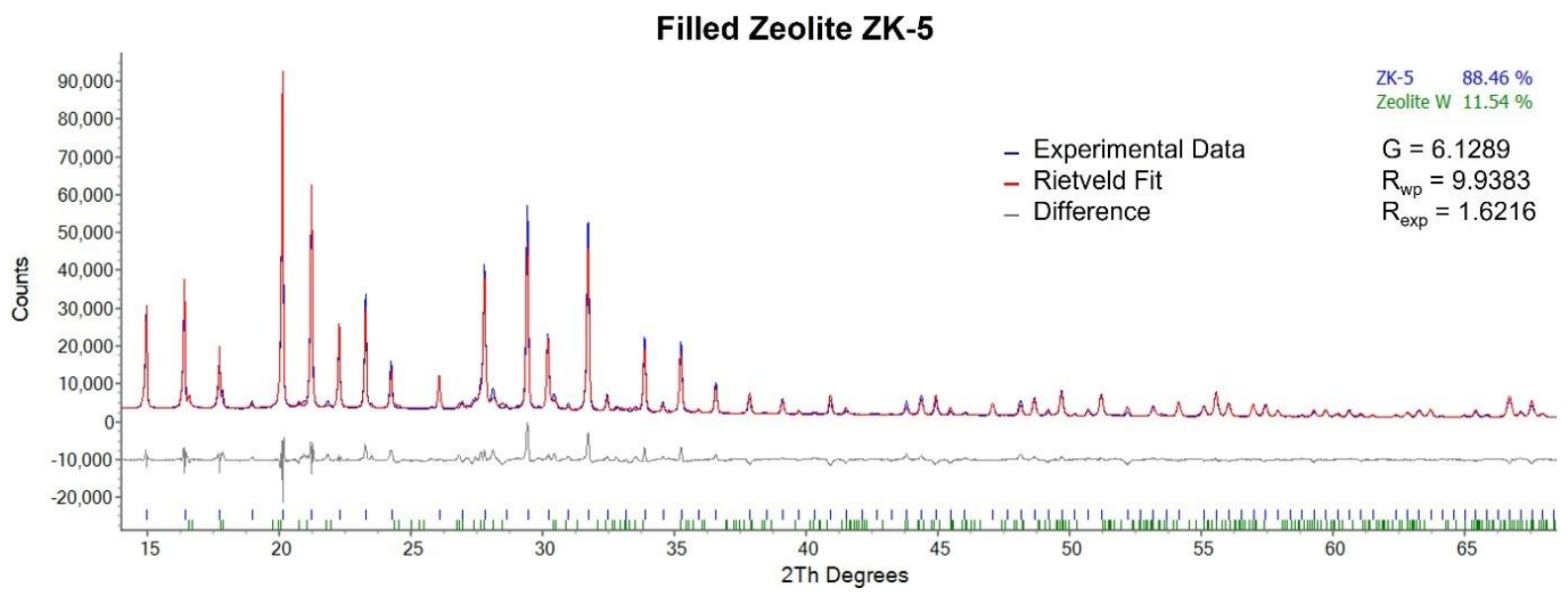

Figure 7. Powder X-ray diffraction patterns for the filled zeolite ZK-5 sample. The experimental data is shown in blue, the Rietveld fit in red and the difference between the two in grey.

Table 4. Final refined unit cell parameters and crystallographic sites for the empty zeolite ZK-5 sample. 'Occ.' refers to the fractional occupancy of the relevant crystallographic site.

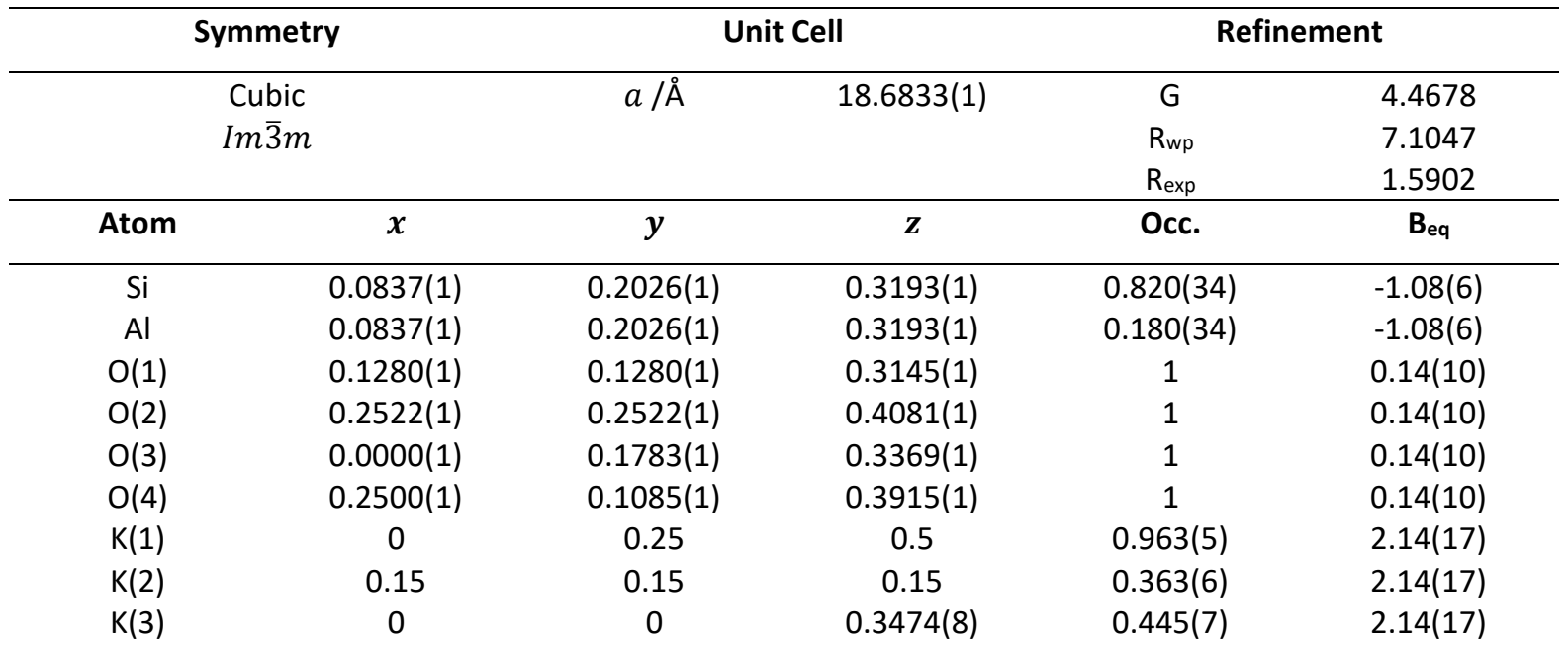




\begin{tabular}{cccccc}
$\operatorname{Ow}(1)$ & $0.1031(6)$ & 0 & 0.5 & $0.952(15)$ & $8.79(46)$ \\
$\operatorname{Ow}(2)$ & 0.3333 & 0.4 & 0.5 & $0.237(8)$ & $8.79(46)$ \\
$\operatorname{Ow}(3)$ & $0.1273(14)$ & $0.1273(14)$ & $0.1273(14)$ & $0.637(6)$ & $8.79(46)$ \\
$\operatorname{Ow}(4)$ & 0 & 0 & $0.2258(15)$ & $0.461(15)$ & $8.79(46)$ \\
\hline
\end{tabular}

Table 5. Final refined unit cell parameters and crystallographic sites for the filled zeolite ZK-5 sample. 'Occ.' refers to the fractional occupancy of the relevant crystallographic site.

\begin{tabular}{|c|c|c|c|c|c|}
\hline \multirow{3}{*}{\multicolumn{2}{|c|}{$\begin{array}{c}\text { Symmetry } \\
\text { Cubic } \\
\text { Im } \overline{3} m\end{array}$}} & \multicolumn{2}{|c|}{ Unit Cell } & \multicolumn{2}{|c|}{ Refinement } \\
\hline & & \multirow[t]{2}{*}{$a / \AA ̊$} & \multirow[t]{2}{*}{$18.6900(1)$} & $\mathrm{G}$ & 6.1289 \\
\hline & & & & $R_{w p}$ & 9.9383 \\
\hline & & & & & \\
\hline Atom & $x$ & $y$ & $\boldsymbol{Z}$ & Occ. & Beq \\
\hline $\mathrm{Si}$ & $0.0825(1)$ & $0.2029(2)$ & $0.3190(1)$ & $0.840(43)$ & $-1.00(6)$ \\
\hline $\mathrm{Al}$ & $0.0825(1)$ & $0.2029(2)$ & $0.3190(1)$ & $0.160(43)$ & $-1.00(6)$ \\
\hline $\mathrm{O}(1)$ & $0.1280(2)$ & $0.1280(2)$ & $0.3145(2)$ & 1 & $-0.03(11)$ \\
\hline $\mathrm{O}(2)$ & $0.2522(2)$ & $0.2522(2)$ & $0.4081(2)$ & 1 & $-0.03(11)$ \\
\hline$O(3)$ & $0.0000(2)$ & $0.1783(2)$ & $0.3369(2)$ & 1 & $-0.03(11)$ \\
\hline $\mathrm{O}(4)$ & $0.2500(2)$ & $0.1085(2)$ & $0.3915(2)$ & 1 & $-0.03(11)$ \\
\hline $\mathrm{K}(1)$ & 0 & 0.25 & 0.5 & $1.000(7)$ & $3.65(19)$ \\
\hline $\mathrm{K}(2)$ & 0.15 & 0.15 & 0.15 & $0.299(9)$ & $3.65(19)$ \\
\hline$K(3)$ & 0 & 0 & $0.3642(6)$ & $0.610(11)$ & $3.65(19)$ \\
\hline$K(4)$ & 0.5 & 0.5 & 0.5 & $0.365(18)$ & $3.65(19)$ \\
\hline$C(1)$ & $0.3234(18)$ & $0.4236(17)$ & 0.5 & $0.243(12)$ & $20.0(25)$ \\
\hline$C(2)$ & $0.3735(11)$ & $0.4468(9)$ & $0.5532(9)$ & $0.360(28)$ & $20.0(25)$ \\
\hline Oc(1) & $0.3830(30)$ & 0.5 & 0.5 & $0.207(25)$ & $9.44(18)$ \\
\hline Oc(2) & 0.4 & 0.4 & 0.4 & $0.357(31)$ & $9.44(18)$ \\
\hline Ow(1) & $0.0868(10)$ & 0 & 0.5 & $0.833(20)$ & $15.1(8)$ \\
\hline Ow(3) & $0.1286(17)$ & $0.1286(17)$ & $0.1286(17)$ & $0.135(8)$ & $15.1(8)$ \\
\hline$O w(4)$ & 0 & 0 & $0.2340(25)$ & $0.547(20)$ & 15.1(8) \\
\hline
\end{tabular}

\section{Metal Cations}

Three crystallographic $\mathrm{K}^{+}$cation sites were determined in the structure of the empty zeolite ZK- 5 and are shown in figure 8 . The first of these is the $K(1)$ site located in the puckered 8-ring opening that links two adjoining orthogonal $t$-pau units. The site has an occupancy of $96 \%$, which the literature has shown to be consistently the most energetically favourable and highest population cation site in KFI-type zeolites. ${ }^{37,46,47}$ It is this observation that strongly suggests that the $\mathrm{K}^{+}$cations play an active role in directing these puckered 8-ring openings, and consequently the KFI framework, during crystallisation. The second cation site determined is the $\mathrm{K}(2)$ site, which is located in the interior of the $\alpha$-cage adjacent to the S6R faces, which adjoin the double 6 -ring (D6R) units between $\alpha$-cages. Lastly there is the $\mathrm{K}(3)$ site positioned within the t-pau units but associated with the 8-ring apertures that connect to the $\alpha$-cage. All three of these cation sites are congruent with those observed for the (Cs,K)-ZK5 zeolite by Parise et al. ${ }^{37}$ with the distinction that the Cs site is occupied by the $\mathrm{K}(3)$ site herein. The sites also agree with the crystal structure reported by Lievens et $a l .{ }^{46}$ for zeolite ZK-5. It is also worth noting that the D6R units in our structure are vacant from occupancy of a $\mathrm{K}^{+}$cation, consistent with calculations by Lievens et al. that this site has a high energy in the KFI framework and is unfavourable to occupy. 
All three cation sites are also seen in the filled zeolite ZK-5 structure, in addition to the K(1) cation site having the greatest occupancy. However, there is the addition of a fourth cation site which is associated with the occluded oxyethylene species. This $K(4)$ site is located at the centre of the $\alpha-$ cage, and is shown alongside the 18C6 species sites in figure 10.

Site $\mathrm{K}(1)$

Occ. $0.963(5)$

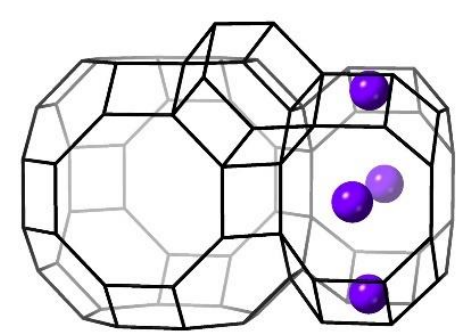

Site $\mathbf{K}(2)$

Occ. $0.363(6)$

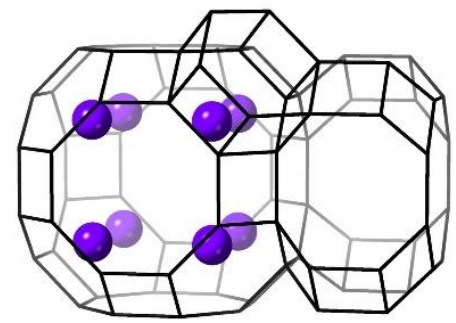

Site $\mathbf{K}(3)$

Occ. $0.445(7)$

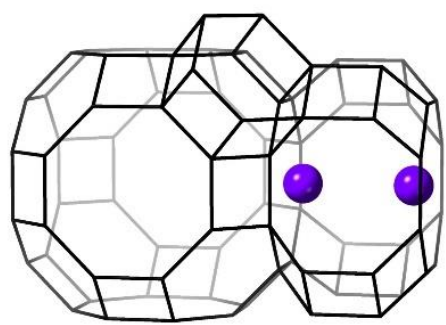

Figure 8. Location of the $\mathrm{K}(1)-\mathrm{K}(3)$ cations sites determined in the empty zeolite ZK-5. The framework is shown as a stick model and the potassium cations as purple spheres. Also included is the fractional occupancy (Occ.) of each site.

\section{Water Molecules}

As the zeolite ZK-5 samples were hydrated when analysed, crystallographic sites for the oxygen atoms in extra-framework water molecules (Ow) were determined. In the empty zeolite four water molecule sites were observed, as shown in figure 9. Site Ow(1) is positioned within the t-pau unit, in the same plane as the $K(1)$ cation site. Based on its location, it is anticipated that the Ow(1) water molecules are coordinated to the $\mathrm{K}(1)$ and $\mathrm{K}(3)$ sites that are likewise in the $t$-pau unit. The occupancy of the Ow(1) site is $95 \%$, comparable to the occupancy of the $K(1)$ site further supporting that this water molecular is coordinated to the $\mathrm{K}(1)$ cation.

The three remaining Ow sites are all positioned within the $\alpha$-cage. The Ow(2) site is represented by a larger cluster in a $\beta$-cage arrangement, with the single 4-rings being parallel to the 8-ring apertures of the $\alpha$-cage. Although there is a large number of positions in the structure, the site only has an occupancy of $24 \%$, averaging as right Ow(2) water molecules per $\alpha$-cage. It is anticipated that the $\mathrm{Ow}(2)$ water molecules are coordinated to the $\mathrm{K}(2)$ cations due to their proximity. The $\mathrm{Ow}(3)$ site is seen to occupy a comparable position to the $K(2)$ site, to the extent that the sites overlap in the average unit cell structure as shown in the Supplementary Information (SI). Therefore, this position is either occupied by a $\mathrm{K}^{+}$cation (36\%) or a water molecule (64\%). Lastly, the Ow(4) was observed to be adjacent to the centre of the 8-ring apertures of the $\alpha$-cage, meaning it is likely coordinated to the $K(3)$ site. According to this structural model each cation site is potentially hydrated by a water molecule.

Concerning the filled zeolite ZK-5 structure, all of the water molecule sites are observed aside from the $\mathrm{Ow}(2)$ site. Instead, the $\mathrm{Ow}(2)$ is replaced by the $C(1)$ carbon site associated with the $18 \mathrm{C} 6$ oxyethylene chain. There are also subtle changes to the occupancy of the remaining water molecule sites. However, such adjustments to the water molecules in the structure are anticipated, as the open framework is instead occupied by the $18 \mathrm{C} 6$ species macromolecule. 
Site Ow(1)

Occ. 0.952(15)

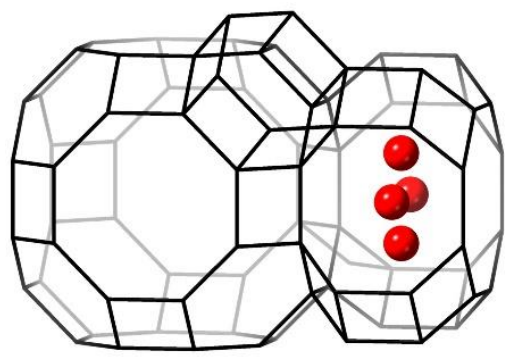

Site Ow(3)

Occ. 0.637(6)

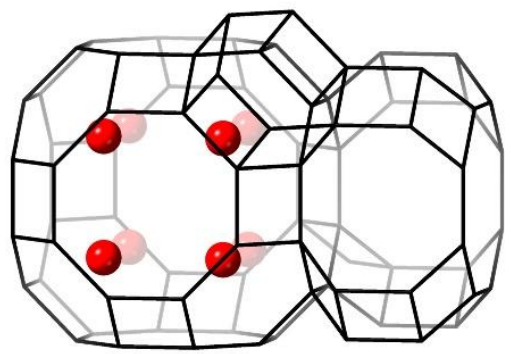

Site Ow(2)

Occ. $0.237(8)$

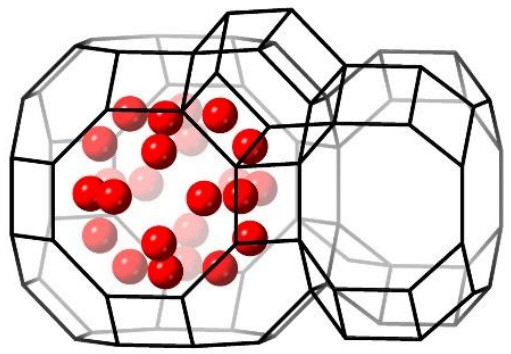

Site Ow(4)

Occ. 0.461(15)

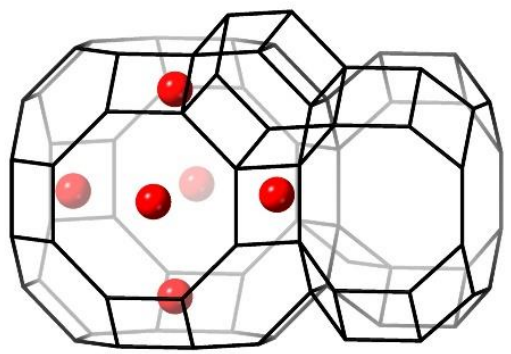

Figure 9. Location of the Ow(1)-Ow(4) water molecule oxygen sites determined in the empty zeolite ZK-5. The framework is shown as a stick model and the water oxygen sites as red spheres. Included is the fractional occupancy (Occ.) of each site.

\section{$18 C 6$ Species}

A total of five crystallographic sites were determined for the occluded $18 \mathrm{C} 6$ species in the filled zeolite ZK-5, including the central K(4) cation site. The remaining four sites belong to the oxyethylene chain, consisting of two carbon and two oxygen sites. As with zeolite RHO, the atomic identity of the four sites were determining by assessing a mixture of the model's goodness of fit, interatomic distances and the chemical formula of 18C6. Figure 10 shows the location of all five of the $18 \mathrm{C} 6$ species crystallographic sites which are situated within the interior of the $\alpha$-cage. The presence of the $\mathrm{K}(4)$ site in the centre of the cluster demonstrates that the occluded $18 \mathrm{C} 6$ species exists as a $\left[(18 \mathrm{C} 6) \mathrm{K}^{+}\right]$macrocation. This is analogous to FAU and EMT-type zeolites where the $\left[(18 \mathrm{C} 6) \mathrm{Na}^{+}\right]$ macrocation exists within the framework supercages. ${ }^{29}$

\section{Site $\mathbf{C}(1)$}

Occ. $0.243(12)$

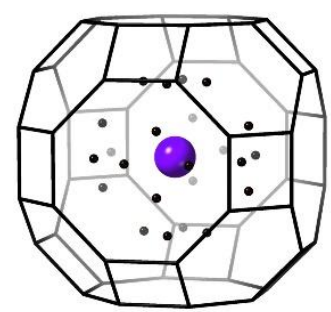

Site $\mathbf{C}(2)$

Occ. $0.360(28)$
Site Oc(1)

Occ. 0.207(25)
Site Oc(2)

Occ. $0.357(31)$
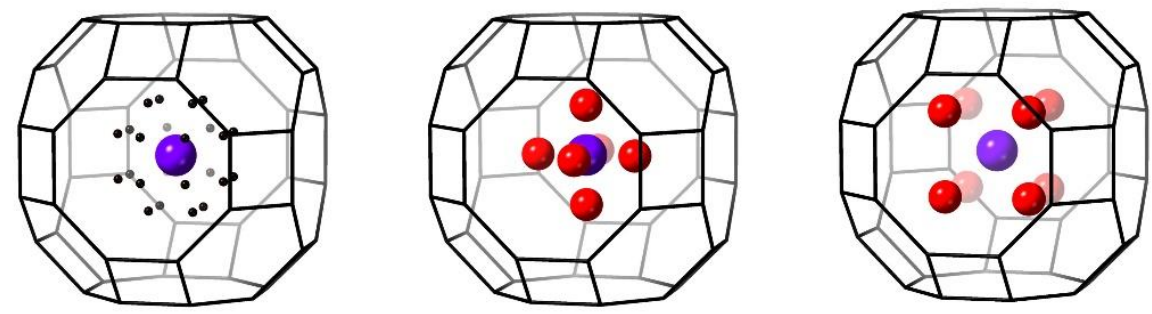
Figure 10. Location of the $C(1), C(2), O c(1)$ and $O c(2)$ sites of the $18 C 6$ oxyethylene chain in the filled zeolite ZK-5. Included is the position of the $\mathrm{K}(4)$ cation site, as shown by a purple sphere. The framework is shown as a stick model, the carbon sites as black spheres and the oxygen sites as red spheres. Also noted is the fractional occupancy (Occ.) of each site.

As seen in zeolite RHO, the structure of the occluded $18 \mathrm{C} 6$ species in zeolite ZK-5 is best described as a cluster. Again, this is likely due to the cubic symmetry of the zeolite, and that $18 \mathrm{C} 6$ species can be aligned along different orientations between adjacent $\alpha$-cages. Moving outwards from the central $\mathrm{K}(4)$ site, there is first a surrounding shell of oxygen Oc(1) sites that each possess an occupancy of $21 \%$. These sites are positioned in an octahedral arrangement and are likely coordinated to the central cation. The next shell consists of the carbon C(2) sites, which have an occupancy of $36 \%$ and are arrayed as vertices of a rhombicuboctahedron. These carbon sites are subsequently surrounded by a shell of Oc(2) oxygen sites in a cubic arrangement, also with an occupancy of $36 \%$. Lastly, the cluster consists of the outer shell of $C(1)$ sites with an occupancy of $24 \%$. Considering the occupancies of each of the crystallographic sites there is less than one macrocation per $\alpha$-cage.

Within the $18 \mathrm{C} 6$ species cluster potential covalent bonds can be evaluated using the expected 1.4 and $1.5 \AA$ lengths for $\mathrm{C}-\mathrm{O}$ and $\mathrm{C}-\mathrm{C}$ bonds in organic ether molecules accordingly. ${ }^{48}$ The interatomic distances between the crystallographic sites that could form possible $\mathrm{C}-\mathrm{C}$ and $\mathrm{C}-\mathrm{O}$ connections are shown in table 6. With the aforementioned threshold, it is clear that the $\mathrm{C}(2)-\mathrm{Oc}(2), \mathrm{C}(2)-\mathrm{Oc}(1)$ and $C(1)-C(2)$ sites may form respective covalent bonds between them. All other distances between carbon and oxygen sites are greater than $1.8 \AA$, meaning it is increasingly less likely that a covalent bond could exist between the sites.

Table 6. The interatomic distances between atoms associated with the oxyethylene chain of the $\left[(18 \mathrm{C} 6) \mathrm{K}^{+}\right]$macrocation cluster in the filled zeolite ZK-5. Listed in ascending order.

\begin{tabular}{cc}
\hline & Interatomic Distance /Å \\
\hline $\mathrm{C}(2)-\mathrm{Oc}(2)$ & $1.331(18)$ \\
$\mathrm{C}(2)-\mathrm{Oc}(1)$ & $1.418(11)$ \\
$\mathrm{C}(1)-\mathrm{C}(2)$ & $1.434(18)$ \\
$\mathrm{C}(1)-\mathrm{Oc}(1)$ & $1.811(30)$ \\
$\mathrm{C}(2)-\mathrm{C}(2)$ & $1.935(11)$ \\
$\mathrm{C}(1)-\mathrm{C}(1)$ & $2.019(18)$ \\
$\mathrm{C}(1)-\mathrm{Oc}(2)$ & $2.396(18)$ \\
\hline
\end{tabular}

\section{Discussion}

In zeolites RHO and ZK-5 it is seen that the occluded $18 \mathrm{C} 6$ species occupies the $\alpha$-cage, as has been expected $^{33,} 34$ but not explicitly proven. We observe that the $18 \mathrm{C} 6$ species is disordered in both zeolites, and hence the structure has been described as a cluster. The reason for this being based on the inherent symmetry of the cubic system, whereby all three crystallographic axes are indistinguishable and the $18 \mathrm{C} 6$ species can be orientated along different directions between unit cells. Consequently, the periodic structure is an average of all these possible orientations, producing the disordered cluster. Furthermore, the absence of a coherent molecule with symmetry match-up with the framework, as seen in zeolite EMC- $2,{ }^{29}$ suggests that the $18 \mathrm{C} 6$ species does not behave as a geometric template in the crystallisation of zeolites RHO and ZK-5. 
Interestingly, both zeolites RHO and ZK-5 can be prepared without the need for $18 \mathrm{C} 6 .{ }^{27,49-51}$ For zeolite $\mathrm{RHO}$ it is the $\mathrm{Cs}^{+}$cations that direct the assembly of the D8Rs, ${ }^{52}$ and in zeolite $\mathrm{ZK}-5$ the $\mathrm{K}^{+}$cations are thought to be involved in the formation of the t-pau units. ${ }^{46}$ In both cases, this behaviour must be sufficient to assemble the relevant framework structure. Therefore, we believe that the $18 \mathrm{C} 6$ species must play a role in stabilising the formation of the $\alpha$-cage, which is supported by its presence in this cavity in both crystal structures. For zeolite RHO it is the non-complexed $18 \mathrm{C} 6$ molecule and in zeolite ZK-5 it is the $\left[(18 \mathrm{C} 6) \mathrm{K}^{+}\right]$macrocation that performs this stabilisation role. The influence of this stabilisation on the actual synthesis of zeolite RHO is that it becomes increasingly facile and expands the crystallisation field. ${ }^{53-56}$ Therefore, we anticipate a similar impact on the synthesis of zeolite ZK-5. Such behaviour would suggest that it influences the free-energy of crystallisation, as we have seen for FAU and EMT-type zeolites. ${ }^{20}$

\section{Conclusions}

Herein, we present the crystal structure of the as-synthesised, $18 \mathrm{C} 6$ containing and calcined analogues of zeolites RHO and ZK-5. We have successfully identified the identity of the occluded $18 \mathrm{C} 6$ species, which in zeolite RHO is an isolated $18 \mathrm{C} 6$ molecule, and in zeolite ZK-5 is a coordinated [(18C6) $\left.\mathrm{K}^{+}\right]$ macrocation. In both zeolites, we observe that the relevant $18 \mathrm{C} 6$ species occupies the $\alpha$-cage cavities. According to the fractional occupancies we predict that there are potentially 2 molecules per cage in the former, and less than one macrocation per cage in the latter. Furthermore, the occluded $18 \mathrm{C} 6$ species are disordered in both periodic frameworks, so we have described the $18 \mathrm{C} 6$ species as a cluster of atomic sites. We believe that this is due to the $18 \mathrm{C} 6$ species being orientated along different directions between adjacent unit cells, which in the cubic symmetry averages to the disordered cluster seen.

Due to the lack of symmetry matchup between the $18 \mathrm{C} 6$ species and the zeolite framework it is deemed that in both cases the relevant $18 \mathrm{C} 6$ species does not behave as a true geometric template. Instead, we believe that the role of the $18 \mathrm{C} 6$ species is better described as a structure directing or space-filling agent. Rather than imprinting symmetry during crystallisation, the $18 \mathrm{C} 6$ species stabilise the open void of the $\alpha$-cage as it is being assembled.

Using these crystal structures, a more coherent understanding of the role of $18 \mathrm{C} 6$ as an organic additive in the synthesis of zeolites can be made. This presents the need for greater appreciation of the multiple available behaviours of organic additives that can be applied to prepare new zeolites.

\section{Acknowledgements}

A.S. thanks the Royal Society for funding. Both A.N. and P.R.R. thank the EPSRC for funding (EP/K004956/1). A.N. thanks Gabriele Kociok-Kohn (of the University of Bath) and Sascha Corell (of STOE \& CIE GmbH) for collecting the X-ray diffraction data for the empty and filled zeolite ZK-5 samples on our behalf. We thank the ESRF Council for accepting our research proposal. We are also grateful to C.D. at the ESRF for assisting with the data collection.

\section{Author Contributions}


The original manuscript was prepared and written by A.N. with input from all the co-authors. Synthesis of the samples was performed by A.N. The high resolution X-ray diffraction data for the zeolite RHO samples were collected by A.N., C.D. and A.S. on the ID22 beamline at the ESRF. The high resolution X-ray diffraction data for the zeolite ZK-5 samples were performed by Gabriele Kociok-Kohn (of the University of Bath) and Sascha Corell (of STOE \& CIE GmbH). A.N. performed the Rietveld refinements using TOPAS Academic and with the assistance of C.D. and A.S. Interpretation of the data and editing of the manuscript was performed by all the authors: A.N., C.D., P.R.R. and A.S.

\section{Data Availability}

All data created during this study is available free of charge from the University of Bath data archive at [URL to be added on acceptance].

\section{Bibliography}

1. Barrer, R. M., Hydrothermal Chemistry of Zeolites. United States Edition ed.; Academic Press Inc. Ltd.: New York, 1982.

2. Jacobs, P. A.; Flanigen, E. M.; Jansen, J. C.; van Bekkum, H., Introduction to Zeolite Science and Practice. Elsevier Science B.V.: Amsterdam, 2010.

3. Li, Y.; Yang, R. T., Hydrogen storage in low silica type $X$ zeolites. The Journal of Physical Chemistry B 2006, 110 (34), 17175-17181.

4. Fisher, J. C.; Siriwardane, R. V.; Stevens Jr, R. W., Zeolite-based process for CO2 capture from high-pressure, moderate-temperature gas streams. Industrial \& Engineering Chemistry Research 2011, 50 (24), 13962-13968.

5. Yeritsyan, H.; Sahakyan, A.; Harutyunyan, V.; Nikoghosyan, S.; Hakhverdyan, E.; Grigoryan, N.; Hovhannisyan, A.; Atoyan, V.; Keheyan, Y.; Rhodes, C., Radiation-modified natural zeolites for cleaning liquid nuclear waste (irradiation against radioactivity). Scientific reports 2013, 3, 2900.

6. Moore, P. B.; Smith, J. V., Archimedean polyhedra as the basis of tetrahedrally-coordinated frameworks. Mineralogical Magazine and Journal of the Mineralogical Society 1964, 33 (266), 10081014.

7. Wilson, S. T., Templating in molecular sieve synthesis. In Verified syntheses of zeolitic materials, Elsevier: 2001; pp 27-31.

8. Cundy, C. S.; Cox, P. A., The hydrothermal synthesis of zeolites: Precursors, intermediates and reaction mechanism. Microporous and Mesoporous Materials 2005, 82 (1-2), 1-78.

9. Brunner, G., A proposal for a mechanism of nucleation in zeolite synthesis. Zeolites 1992, 12 (4), 428-430.

10. Burkett, S. L.; Davis, M. E., Mechanism of structure direction in the synthesis of pure-silica zeolites. 2. Hydrophobic hydration and structural specificity. Chemistry of materials 1995, 7 (8), 14531463.

11. Burkett, S. L.; Davis, M. E., Mechanisms of structure direction in the synthesis of pure-silica zeolites. 1. Synthesis of TPA/Si-ZSM-5. Chemistry of materials 1995, 7 (5), 920-928.

12. Flanigen, E. M.; Bennett, J.; Grose, R.; Cohen, J.; Patton, R.; Kirchner, R.; Smith, J., Silicalite, a new hydrophobic crystalline silica molecular sieve. Nature 1978, 271 (5645), 512-516.

13. Oleksiak, M. D.; Rimer, J. D., Synthesis of zeolites in the absence of organic structure-directing agents: factors governing crystal selection and polymorphism. Reviews in Chemical Engineering 2014, $30(1), 1-49$. 
14. Baerlocher, C.; McCusker, L. B. Database of Zeolite Structures. http://www.izastructure.org/databases/ (accessed 09/01/16).

15. Lobo, R. F.; Zones, S. I.; Davis, M. E., Structure-direction in zeolite synthesis. Inclusion Chemistry with Zeolites: Nanoscale Materials by Design 1995, 47-78.

16. Davis, M. E.; Lobo, R. F., Zeolite and molecular sieve synthesis. Chemistry of Materials 1992, 4 (4), 756-768.

17. Cox, P. A.; Casci, J. L.; Stevens, A., Molecular modelling of templated zeolite synthesis. Faraday Discussions 1997, 106, 473-487.

18. Zones, S. I.; Nakagawa, Y., Boron-beta zeolite hydrothermal conversions: the influence of template structure and of boron concentration and source. Microporous Materials 1994, 2 (6), 543555.

19. Fletcher, R. E.; Wells, S. A.; Leung, K. M.; Edwards, P. P.; Sartbaeva, A., Intrinsic flexibility of porous materials; theory, modelling and the flexibility window of the EMT zeolite framework. Acta Crystallographica Section B: Structural Science, Crystal Engineering and Materials 2015, 71 (6), 641647.

20. Nearchou, A.; Cornelius, M.-L. U.; Skelton, J. M.; Jones, Z. L.; Cairns, A. B.; Collings, I. E.; Raithby, P. R.; Wells, S. A.; Sartbaeva, A., Intrinsic flexibility of the EMT zeolite framework under pressure. Molecules 2019, 24 (3), 641.

21. Stevens, A. P.; Gorman, A. M.; Freeman, C. M.; Cox, P. A., Prediction of template location via a combined Monte Carlo-simulated annealing approach. Journal of the Chemical Society, Faraday Transactions 1996, 92 (12), 2065-2073.

22. Lewis, D. W.; Willock, D. J.; Catlow, C. R. A.; Thomas, J. M.; Hutchings, G. J., De novo design of structure-directing agents for the synthesis of microporous solids. Nature 1996, 382 (6592), 604606.

23. Lewis, D. W.; Freeman, C. M.; Catlow, C. R. A., Predicting the templating ability of organic additives for the synthesis of microporous materials. Journal of Physical Chemistry 1995, 99 (28), 11194-11202.

24. Chatelain, T.; Patarin, J.; Farre, R.; Petigny, O.; Schulz, P., Synthesis and characterization of 18-crown-6 ether-containing KFI-type zeolite. Zeolites 1996, 17 (4), 328-333.

25. Chatelain, T.; Patarin, J.; Soulard, M.; Guth, J. L.; Schulz, P., Synthesis and characterization of high-silica EMT and FAU zeolites prepared in the presence of crown-ethers with either ethylene-glycol or 1,3,5-trioxane. Zeolites 1995, 15 (2), 90-96.

26. Chatelain, T.; Patarin, J.; Fousson, E.; Soulard, M.; Guth, J. L.; Schulz, P., Synthesis and characterization of high-silica zeolite-rho prepared in the presence of 18-crown-6 ether as organic template. Microporous Materials 1995, 4 (2-3), 231-238.

27. Robson, H., Verified Syntheses of Zeolitic Materials. Second Revised Edition ed.; Elsevier Science B.V.: Amsterdam, 2001; p 265.

28. Nearchou, A.; Raithby, P. R.; Sartbaeva, A., Systematic approaches towards template-free synthesis of EMT-type zeolites. Microporous and Mesoporous Materials 2018, 255, 261-270.

29. Baerlocher, C.; McCusker, L. B.; Chiappetta, R., Location of the 18-crown-6 template in EMC2 (EMT) Rietveld refinement of the calcined and as-synthesised forms. Microporous Materials 1994, 2 (4), 269-280.

30. Terasaki, O.; Ohsuna, T.; Alfredsson, V.; Bovin, J. O.; Watanabe, D.; Carr, S. W.; Anderson, M. W., Observation of spatially correlated intergrowths of faujastic polytypes and the pure end members by high-resolution electron microscopy. Chemistry of Materials 1993, 5 (4), 452-458.

31. Ohsuna, T.; Terasaki, O.; Alfredsson, V.; Bovin, J. O.; Watanabe, D.; Carr, S. W.; Anderson, M. W., Observations on the role of crown ether templates in the formation of hexagonal and cubic polymorphs of zeolite Y. Proceedings of the Royal Society a-Mathematical Physical and Engineering Sciences 1996, 452 (1946), 715-740.

32. Burkett, S. L.; Davis, M. E., Structure-directing effects in the crown ether-mediated synthesis of FAU and EMT zeolites. Microporous Materials 1993, 1 (4), 265-282. 
33. Nearchou, A.; Armstrong, J.; Butler, K. T.; Raithby, P. R.; Sartbaeva, A., Differentiating the role of organic additives to assemble open framework aluminosilicates using INS spectroscopy. Physical Chemistry Chemical Physics 2020, 22 (25), 14177-14186.

34. Chatelain, T.; Patarin, J.; Brendle, E.; Dougnier, F.; Guth, J. L.; Schulz, P., Synthesis of highsilica FAU-, EMT-, RHO- and KFI-type zeolites in the presence of 18-crown-6 ether. Studies in Surface Science and Catalysis 1997, 105, 173-180.

35. Coelho, A. A., TOPAS and TOPAS-Academic: an optimization program integrating computer algebra and crystallographic objects written in C++. Journal of Applied Crystallography 2018, 51 (1).

36. Parise, J. B.; Cox, D. E., Structural changes occurring upon dehydration of zeolite Rho. A study using neutron powder diffraction and distance-least-squares structural modeling. The Journal of Physical Chemistry 1984, 88 (8), 1635-1640.

37. Parise, J. B.; Shannon, R. D.; Prince, E.; Cox, D., The crystal structures of the synthetic zeolites (Cs, K)-ZK5 and (Cs, D)-ZK5 determined from neutron powder diffraction data. Zeitschrift für Kristallographie-Crystalline Materials 1983, 165 (1-4), 175-190.

38. Toby, B. H., R factors in Rietveld analysis: How good is good enough? Powder diffraction 2006, $21(1), 67-70$.

39. Merritt, E. A., Some $B_{\text {eq }}$ are more equivalent than others. Acta Crystallographica Section A: Foundations of Crystallography 2011, 67 (6), 512-516.

40. Baerlocher, C.; McCusker, L. B.; Olson, D. H., Atlas of Zeolite Framework Types. 6th ed.; Elsevier: Amsterdam, 2007; p 405.

41. Robson, H. E.; Shoemaker, D. P.; Ogilvie, R. A.; Manor, P. C., Synthesis and crystal-structure of zeolite Rho - A new zeolite related to Linde Type-A. Advances in Chemistry Series 1973, (121), 106115.

42. Parise, J. B.; Gier, T. E.; Corbin, D. R.; Abrams, L.; Jorgensen, J. D.; Prince, E., Flexibility of the framework of zeolite Rho. Structural variation from 11 to $573 \mathrm{~K}$. A study using neutron powder diffraction data. The Journal of Physical Chemistry 1984, 88 (11), 2303-2307.

43. Nearchou, A.; Cornelius, M.-L. U.; Jones, Z. L.; Collings, I. E.; Wells, S. A.; Raithby, P. R.; Sartbaeva, A., Pressure-Induced Symmetry Changes in Body-Centered Cubic Zeolites. 2018.

44. Lee, Y.; Hriljac, J. A.; Vogt, T.; Parise, J. B.; Edmondson, M. J.; Anderson, P. A.; Corbin, D. R.; Nagai, T., Phase transition of zeolite RHO at high-pressure. Journal of the American Chemical Society 2001, 123 (34), 8418-8419.

45. Meier, W. M.; Kokotailo, G. T., The crystal structure of synthetic zeolite ZK-5. Zeitschrift für Kristallographie-Crystalline Materials 1965, 121 (1-6), 211-219.

46. Lievens, J. L.; Verduijn, J. P.; Mortier, W. J., Cation site energies in dehydrated KFI-type zeolites: d-NaKFI, d-NaHKFI, and d-KKFI. Zeolites 1992, 12 (6), 690-697.

47. Treacy, M. M.; Higgins, J. B., Collection of simulated XRD powder patterns for zeolites fifth (5th) revised edition. Elsevier: 2007.

48. Allen, F. H.; Kennard, O.; Watson, D. G.; Brammer, L.; Orpen, A. G.; Taylor, R., Tables of bond lengths determined by $\mathrm{X}$-ray and neutron diffraction. Part 1 . Bond lengths in organic compounds. Journal of the Chemical Society, Perkin Transactions 2 1987, (12), S1-S19.

49. Nearchou, A.; Sartbaeva, A., Influence of alkali metal cations on the formation of zeolites under hydrothermal conditions with no organic structure directing agents. Crystengcomm 2015, 17 (12), 2496-2503.

50. Robson, H. E. Method for preparing a small pore synthetic zeolite. 1973.

51. Verduijn, J. P., Zeolite ZK-5. Google Patents: 1991.

52. Liu, S.; Zhang, P.; Meng, X.; Liang, D.; Xiao, N.; Xiao, F.-S., Cesium-free synthesis of aluminosilicate RHO zeolite in the presence of cationic polymer. Microporous and Mesoporous Materials 2010, 132 (3), 352-356.

53. McCusker, L. B.; Baerlocher, C. The Sixth International Zeolite Conference, Butterworths, Guildford: 1983; p 812. 
54. Barrer, R. M.; Barri, S.; Klinowski, J. The Fifth International Zeolite Conference, Heyden, London: 1980; p 20.

55. Araki, S.; Kiyohara, Y.; Tanaka, S.; Miyake, Y., Adsorption of carbon dioxide and nitrogen on zeolite rho prepared by hydrothermal synthesis using 18-crown-6 ether. Journal of Colloid and Interface Science 2012, 388, 185-190.

56. Araki, S.; Kiyohara, Y.; Tanaka, S.; Miyake, Y., Crystallization process of zeolite rho prepared by hydrothermal synthesis using 18-crown-6 ether as organic template. Journal of Colloid and Interface Science 2012, 376, 28-33. 